\title{
HDM2-binding Peptide PNC-27
}

National Cancer Institute

\section{Source}

National Cancer Institute. HDM2-binding Peptide PNC-27. NCI Thesaurus. Code C136515.

A human double minute 2 (HDM2)-binding peptide comprised of a carboxy terminal p53 leader sequence (amino acids 12-26) linked to a membrane residency peptide (MRP), which facilitates penetration of the tumor cell plasma membrane, with potential antineoplastic activity. HDM2-binding peptide PNC-27 binds to HDM2, which is expressed in the plasma membrane of certain cancer cells, and induces transmembrane pore formation, resulting in tumor cell necrosis that is independent of p53 activity. HDM2, a zinc finger protein and negative regulator of the p53 pathway, is often overexpressed by cancer cells and has been implicated in cancer cell proliferation and survival. 